\title{
The living status in china's disabled elderly--taking an example of luoyang
}

\begin{abstract}
Through the Luoyang City-the third line city of China, This article will further illustrate the shifting patterns of Chinese old people's endowment pattern, especially the current situation of the disabled elderly. The aim of this paper is to arouse the whole society to pay more attention to those people who lose their basic abilities to look after themselves.
\end{abstract}

Volume 3 Issue 5 - 2017

\author{
Huang Yang \\ Student counsellor, Luoyang Institute of Science and Technology, \\ China
}

Correspondence: Huang Yang, Student Counsellor, Luoyang Institute of Science and Technology, China,

Email maryhuang72@I63.com

\section{Introduction}

It is generally believed that China has entered an aging society since 1991, and the "silver wave" has not been about to date, the degree of the aging population has been continuously strengthened and the elderly have sharply increased. However, the current medical service level of the elderly in China is relatively low, therefore, the today's situation of inadequate medical conditions for the elderly may cause the elderly and their families to live under great pressure, the pension problem and so on. ${ }^{1}$

\section{The high proportion of incapacitating old people}

According to China's old office released the 2010 statistics bulletin of the China aging development, China's older population aged 60 and above 177.65 million, which accounts for $13.26 \%$ of the total population. At the same time, China's urban and rural parts of disability and complete disability old people about 33 million, accounting for $19.0 \%$ of the overall aging population.

\section{Traditional caring patterns}

Generally speaking, nowadays, China's population has the characteristics of advanced age, high speed and large quantity. Consequently, who will be responsible for looking after the elderly is a big issue, which we have to face it.

Traditionally, it is widely acceptable that the next of kin will take responsibility for caring people with disability at home in China. This is a custom that has been handed down from Confucius since thousands years ago. Cooney and $\mathrm{Di}^{2}$ demonstrate that if an old person with disability is widowed, his/her older daughter probably becomes the principle caregiver in Chinese society. In addition, with the increasing of elderly population and the change of family structure, nowadays, Chinese families have generally carried out " 421 family" pattern - that is, a couple supports four elderly adults and one child. This is because the average family's population is shrinking, which shows urban households on average about only 2.9 people, rural families, on average, about 3.8 people, family endowment functions are weakening.

\section{Discussion}

As mentioned above, these caring models raise a series of serious problems. With respects to a mother/adult daughter model of nursing care, an interpretive descriptive study demonstrates that adult daughters tend to be the principle caregivers if their mothers are widowed, daughters are unemployed or they live more closely. ${ }^{3}$ Nevertheless, if the daughter is employed, who can replace her to take care of her parents? Brothers or sisters or other relatives? In the countryside, it may be practical because rural families usually have at least two children; but in the cities, it may be not practical due to being strictly carried out family planning. Therefore, these will bring an unsolvable issue. This means that previous intergeneration care by inheriting Confucian thoughts is faced with a major challenge.

It is generally believed that after age 75 , the health condition of older adults will get more worse, and it may result in morbidity and their abilities to self-care tend to gradually decline day by day. As a consequence, daily care, life care and other services are becoming increasingly important and necessary. At present, China's urban pension model has four modes: old-age nursing home, family bed, home care and community care.

\section{Luoyang's endowment pattern}

Taking Luoyang for an example, which is author's hometown and is also a third line city with 2 million population, its current pension model is the "remote diagnosis and treatment" service mode of the combination mode of medical care. Specifically, the biggest hospital in Luoyang, called the first affiliated hospital of Henan university of science and technology, signed endowment service with Yichuan, Jianxi as well as Luolong district in order to provide high-quality medical services for the senior pensioners in local nursing homes. Currently, relying on the Internet hospital of the first affiliated hospital of Henan university of science and technology, my hometown can provide free access to health care, counseling, health guidance, medical treatment and other green channel services for the old-age pension institutions. ${ }^{4}$

\section{Uncle zhang is beneficial for combination of medical care}

The author's neighbor, Uncle Zhang, is one of the beneficial owners. He was diagnosed with dementia five years ago. At that moment, his wife just died of lung cancer and since then he became a person who needs to be taken care of at every minute. Two years ago, his only son suffered from chronic diseases due to long term caring for him. Because of anxiety and fatigue, 34-year old Xiao Zhang looks 
very weak and depressed. It is said that he often makes a mess of his work and life. More worse, he had depression two years ago. Since the implementation of combination of medical care, Uncle Zhang has enjoyed the professional care in the community pension service center and meanwhile, Xiao Zhang can also balance between life and work. These changes are due to the combination of medical care and nursing care.

\section{Aunt li is beneficial for hotline service}

In 2011, the author's hometown Luoyang became the first in Henan province to introduce social capital and build a 12349 home pension information service platform. Increasingly more people, like Aunt Li, join the hotline service. Before last May, Aunt Li, a 77-year old woman, did not know what the "12349" hotline was. Buying life supplies and ingredients, she has to go to supermarkets, run the vegetable fields, repeatedly compare prices, carry them to home again, eventually; she suffered from the severe back pain. Now, dial a telephone, buying 20 catty noodles, the morning order, afternoon arrive goods, sell price 40.8yuan, comparing the market price 1.2 yuan. $^{4}$

In 2015 , the hotline number was nearly 3 million. According to the governmental plan, Luoyang old-age service information network will realize the four-level interconnection of village and countryside, covering both urban and rural areas. So far, Luoyang city has about 1.03 million people over the age of 60 , and the information of 820,000 elderly people is now enrolled in the 12349 platform. ${ }^{4}$ Overall, through the Internet, Luoyang City nowadays changes the pension model and builds nursing homes without walls in order to meet all needs of its citizens.

\section{Conclusion}

The Internet has opened a new way for "pension and medical care" and innovated the service model. I believe that in the future, increasingly more Chinese cities will take more practical approaches to offer good services to the elderly, especially for the disabled elderly.

\section{Acknowledgements}

None.

\section{Conflict of interest}

The author declares no conflict of interest.

\section{References}

1. Fan X. The present situation and prospect of nursing model of urban elderly in China. Chinese recuperation medicine. 2011;20(9):821-822.

2. Cooney RS, Di JX. Primary family caregivers of impaired elderly in Shanghai, China. Research on Ageing. 1999;21(6):739-761.

3. Ward-Griffin C, Oudshoorn A, Clark K, et al. Mother-adult daughter relationships within dementia care: a critical analysis. $J$ Fam Nurs. 2007;13(1):13-32.

4. Yang XL. Research on the development of nursing mode of nursing care in China. Medical frontier. 2015;5(34):17-18. 